\title{
Process Evaluation of a Policy, Systems, and Environmental Change Intervention in an Urban School District
}

\author{
Silvia Lepe, MS, RDN; Jennifer Goodwin, MS, RDN; Katie T. Mulligan, MS, RDN; \\ Kate Balestracci, PhD, RDN; Linda Sebelia, MA, MS, RDN; Geoffrey Greene, PhD, RDN
}

\begin{abstract}
Objective: To conduct a comprehensive process evaluation of a policy, systems, and environmental (PSE) change intervention.

Design: Quasi-experimental, mixed methods.

Setting: Low-income urban school district.

Participants: Fifth-grade students in 4 schools assigned to 2 intervention and 2 comparison schools (intervention, $\mathrm{n}=142$; comparison, $\mathrm{n}=170)$.

Intervention: Both groups received a nutrition curriculum delivered by classroom teachers. Intervention schools also received 10 PSE lessons taught by paraprofessional educators.

Main Outcome Measures: Quantitative data were obtained from fidelity and observation checklists, grading rubrics and self-reported student surveys. Focus group and interviews provided qualitative data. Quantitative measures included assessments of PSE and fruit and vegetable knowledge, as well as assessment of times fruits and vegetables (FV) were consumed yesterday.

Analyses: Qualitative data were analyzed using inductive content analysis. Quantitative data were analyzed using repeated measures analysis of variance and analysis of co-variance.

Results: Fidelity, dose, reach, and acceptance of PSE intervention were high; students felt more empowered, although PSE lessons were considered lengthy and complicated. Intervention PSE and FV knowledge scores were significantly higher than comparison scores $\left(\mathrm{F}_{37.56}, P<.001\right.$; and $\mathrm{F}_{3.94}, P<.05$, respectively). However, issues in communication were identified between school staff and researchers.

Conclusions and Implications: Policy, systems, and environmental classroom interventions commented on the differences between quantitative and qualitative assessments, and this suggests the need for more sensitive quantitative assessments. Future research should look at long-term outcomes as this study only looked at short-term outcomes.
\end{abstract}

Key Words: food and nutrition policy, policy, school nutrition, student empowerment, systems and environment (J Nutr Educ Behav. 2019; 51:307-317.)

Accepted July 27, 2018. Published online September 28, 2018.

\section{INTRODUCTION}

Given the important role that environment has on food choice, public health interventions are increasingly implementing strategies involving policy, systems, and environmental (PSE) change. ${ }^{1}$ Policy, systems, and environmental interventions focus on several circles of influence within the socioecological model to change and sustain healthy community behaviors. ${ }^{2}$ In contrast to individual or small-group interventions, PSE programs offer strategies with greater population impact than individual change strategies by making healthy choices easy and convenient. ${ }^{3-5}$

Schools are viable locations for PSE interventions because they are existing infrastructures conducive to integrative coordination and collaboration among systems. ${ }^{6}$ In addition to classroom nutrition education, ${ }^{7,8}$

\footnotetext{
Department of Nutrition and Food Sciences, University of Rhode Island, Providence, RI Conflict of Interest Disclosure: The authors have not stated any conflicts of interest.

Address for correspondence: Linda Sebelia MA, MS, RDN, Department of Nutrition and Food Sciences, University of Rhode Island, 80 Washington St, Ste 300, Providence, RI 02903; E-mail: sebelia@uri.edu

(C) 2018 Society for Nutrition Education and Behavior. Published by Elsevier Inc. All rights reserved.
}

https://doi.org/10.1016/j.jneb.2018.07.017 interventions to improve eating behaviors appear to be more successful when they include policy change, input from multiple parties (students, parents, and school staff), and environmental change. ${ }^{9,10}$ These interventions within the school environment can be designed to empower children to be involved in changes that directly affect them, making them more likely to incorporate these changes into their daily routines ${ }^{11,12}$ and having a strong positive effect on their selfesteem and ability to drive change. ${ }^{13}$ Involvement in activities such as participating in wellness committee meetings or suggesting ways to improve the school cafeteria environment ${ }^{11,13}$ gives children a voice in enacting positive change to the school food environment. 
Because US children are not meeting recommended intakes for fruits and vegetables $(\mathrm{FV})^{14}$ and schoolbased classroom nutrition education can have positive impacts on knowledge and behavior, ${ }^{7,8,11,15,16}$ FV classroom interventions incorporating PSE components seem warranted. However, there are a limited number of studies measuring outcomes of a PSE intervention on FV intake or on PSE and FV knowledge; and because PSE interventions are relatively new, there is a need for additional process evaluation research with these programs. ${ }^{11,15,17-19}$ The primary aim of this pilot study was to conduct a comprehensive process evaluation of a novel PSE intervention. It was hypothesized that process evaluation results would demonstrate that (1) intervention fidelity and dose, as well as student engagement, understanding, participation, and reach, would be $\geq 80 \%$; and (2) students, school staff, and educators would evaluate the program positively. The secondary aim was to examine change in short-term outcomes, comparing the PSE intervention group with a group using a quasi-experimental design. It was hypothesized that students in the intervention group would increase FV intake and PSE and FV knowledge more than would students in the comparison group.

\section{METHODS}

\section{Study Overview}

This quasi-experimental, mixed-methods pilot study was part of the University of Rhode Island (URI) Community Nutrition Education Program (Supplemental Nutrition Assistance ProgramEducation [SNAP-Ed] and Expanded Food and Nutrition Education Program [EFNEP]), entitled Empowering Urban School Children to Increase Fruit and Vegetable Consumption Through EFNEP-Enhanced PSE Interventions (EMPOWER). The EMPOWER consisted of 10 30-minute PSE lessons designed to be delivered every other week by trained EFNEP staff. It was designed to augment the 8-week URI SNAP-Ed Fresh Fruit and Vegetable Program (FFVP) Nutrition Education Curriculum that focused on increasing $\mathrm{FV}$ consumption by elementary school students. In addition, the schools participated in the US Department of Agriculture FFVP, ${ }^{20}$ which provides an additional serving of FV to children in low-income elementary schools as a snack, independent of school breakfast or lunch. ${ }^{16}$ Both intervention and comparison schools were to receive the FFVP Nutrition Education Curriculum delivered by school health teachers trained by SNAP-Ed staff. Intervention schools would receive the additional PSE education component delivered by 3 EFNEP paraprofessional educators who participated in 2 2-hour training sessions on the new PSE curriculum and received an indepth orientation to process evaluation methodology. The study was composed of 2 concurrent phases: a process evaluation (September, 2015 to May, 2016) and an outcome evaluation (October, 2015 to May, 2016). The process evaluation followed the methodology of Saunders et al, ${ }^{21}$ starting with a detailed process evaluation plan identifying (1) process evaluation elements of program fidelity, dose delivered, dose received, reach, and perception of the program; (2) specific questions to evaluate achievements of these elements, eg, to what extent each of the program's lessons were implemented as planned; and (3) the instrument, such as educator and evaluator fidelity checklists, attendance, and assignment completion forms, or method of approach, such as focus groups and interviews. Outcome evaluation used a quasi-experimental pre-post design with schools assigned to intervention or control conditions.

\section{Study Participants}

Based on working relationships, a convenience sample of 4 schools was chosen by URI SNAP-Ed staff and researchers. Fifth-grade students $(\mathrm{n}=142)$ from 6 classrooms in 2 schools were assigned to the intervention arm; 170 from 6 classrooms in the 2 other schools were assigned to the comparison group. The target population was racially and ethnically diverse (35\% white, 31\% Hispanic, and $26 \%$ black or African American) from low-income households (72\% received free or reducedprice meals). ${ }^{22-24}$
As a part of process evaluation, 2 student focus groups were conducted, 1 per intervention school. The focus groups consisted of 5 intervention students per school, recruited at random by fifth-grade teachers. One additional focus group included the 3 EFNEP educators involved in the study. Key informant interviews included 1 intervention school principal, 1 foodservice representative for the district, one wellness committee member, and 2 health teachers (1 from each school). The study was part of URI Institutional Review Board's exempt status for SNAP-Ed and EFNEP.

\section{Description of Intervention}

The PSE lessons were designed to empower students to change their school environment and improve FV intake by participating in several different activities (Table 1). Like strategies used by other PSE initiatives, ${ }^{25}$ the PSE lessons empowered students to make changes in their cafeteria environment through recipe and menu development as well as messaging and advertising changes. ${ }^{25}$ In addition, students and parents were encouraged to attend wellness committee meetings. Parents received newsletters every other lesson (a total of 5) throughout the intervention to inform them about program activities. After the intervention, letters were written by the EFNEP director to the wellness committee, describing the intervention and results.

\section{Evaluation}

Process evaluation phase. The EFNEP educators documented delivery of PSE lessons. Elements evaluated included fidelity, dose delivered and received, reach, and program perceptions. The SNAP-Ed staff attended 3 lessons per educator and documented those elements. Finally, rubrics were created to evaluate whether students were successful in understanding lesson and/or activity objectives for each of the 3 takehome assignments. One SNAP-Ed staff member trained on the scoring process graded each submitted assignment by checking whether assignment criteria were met. The rubrics were created by the graduate 


\section{Table 1. Description of Policy, Systems, and Environment Lessons for the EMPOWER Intervention}

\section{Policy, Systems, and Environment Lessons}

1. Fruits and Vegetables You Enjoy

\section{Overcoming Barriers}

3. Let's Read a Recipe!

4. It's Time to Role-play!

5. Making Requests

6. Taste Testing

7. Media and Food Ads

\section{Advertisements}

9. Persuasive Messages

10. Taking a Poll

Wrap-up

\section{Description}

Students discuss FV they enjoy and draft a letter to the wellness committee about adding these FV to the lunch menu.

Students discuss barriers to eating FV and how to communicate this with the wellness committee.

Students learn about all of the different components of a recipe in preparation for interviewing a parent at home for an FV-based recipe.

Students learn how to interview their parents about an FV-based recipe they eat at home.

Students learn a constructive way to tell their parents which FV they like best.

Students taste test FV-based recipes brought in from home and vote on the 1 they like best (the winning recipe).

Students learn about advertising and slogans in preparation for advertising the winning recipe around the school.

Students create slogans and brainstorm ideas for posters to advertise the winning recipe around the school.

Students brainstorm ideas for persuasive messages to promote the winning recipe during morning school announcements.

Students learn how to poll the rest of the student body about whether they like the winning recipe. The winning recipe was sampled by the entire student body.

The winning recipe was added to the school menu. Students assisted in creating a letter to the wellness committee to disseminate intervention results. The EATMORE Fruits and Veggies Recipe Book, which included all recipes submitted by fifth-graders, was printed and provided to all fifth-graders in participating schools.

EMPOWER indicates Empowering Urban School Children to Increase Fruit and Vegetable Consumption Through Expanded Food and Nutrition Education Program-Enhanced Policy, Systems, and Environmental Interventions; FV, fruits and vegetables.

student researcher and reviewed by SNAP-Ed staff and the EFNEP team. Student focus group guides were pilot-tested with nonparticipating fifth-grade students and revised for final use. The EFNEP focus group guide was based on previously tested items from earlier SNAP-Ed interventions (these items were also used for interviews). Focus groups (each 30 minutes long) and key informant interview responses, recorded by a notetaker, captured successes, barriers, and challenges regarding the intervention. All responses were recorded as close to verbatim as possible. The moderator was a graduate student; the assistant moderator was the SNAP-Ed program manager. Table 3 presents the tools used, collection details, and the evaluator category. All materials are available upon request from the corresponding author.

Outcome evaluation phase. Student demographics were collected at baseline using the SNAP-Ed Child/Youth Participant Survey Form. ${ }^{26}$ Items assessed age, attendance at URI
SNAP-Ed workshops in the past year, gender, language spoken at home (to determine ethnicity), and race. Based on the validated SNAP-Ed FV Checklist, ${ }^{27}$ the total number of times (from 0 to $\geq 5$ ) a fruit and/or vegetable was consumed on the previous day was assessed. Students also completed a prepost assessment to evaluate change in knowledge. The instrument, which was developed for the study, assessed PSE knowledge ( 7 items, scored 0 [incorrect] or 1 [correct]; in which $0=$ low and $7=$ high) and FV knowledge (9 items, scored 0 [incorrect] or 1 [correct]; in 
which $0=$ low and $9=$ high). Face validity was determined by SNAP-Ed nutrition educators. One cognitive interview $^{28}$ conducted by the graduate student and SNAP-Ed program manager with 5 fifth-grade students from a different school district (a partner school with similar student demographics) indicated that students understood all knowledge items.

\section{Analysis}

Process evaluation phase. Quantitative data from the self-reported fidelity checklists, observation checklists, and grading rubrics were transferred into Microsoft Excel 2011 (Microsoft Corporation, Redmond, WA), which was used to analyze descriptive results. All handwritten comments from fidelity and observation checklists were typed into a structured template. Responses from focus groups and key informant interviews were typed and reviewed by the researchers with the notetaker to discuss initial findings and impressions. All checklist comments, focus groups, interviews, and meeting minutes were entered into NVivo (version 11, QSR International, Melbourne Australia, 2017). Inductive content analysis ${ }^{29}$ was used for qualitative assessment. The first author, who was trained by an expert committee member, generated codes through the process of open coding. Codes were then categorized to form higher-order categories which led to abstraction to determine the 4 main themes of analysis. $^{29}$ Emergent themes are illustrated by selected anonymous participant feedback.

Outcome evaluation phase. All data were analyzed using SPSS (version 24 for Windows, IBM, Armonk, NY, 2017). Demographic information was analyzed using independent-sample $t$ tests or Pearson chi-square tests of independence. The FV variables were normally distributed with no differences in baseline FV consumption; fruits and vegetables were combined for analysis. Between-group change in FV consumption was analyzed using repeated-measures ANOVA (dependent variable $\times 2$ groups $\times 2$ occasions). To account for baseline differences between groups, ANCOVA was run for between-group changes for the 2 knowledge variables with baseline variable as a covariate. Within-group differences for FV intake, PSE knowledge, and FV knowledge were measured using paired $t$ tests.

\section{RESULTS}

Table 2 provides a description of the sample population. On average, the children were aged $10.19 \pm 0.45$ years, relatively evenly split by gender; $36 \%$ reported speaking Spanish at home. Hence, intervention materials such as newsletters were provided in both English and Spanish.

Table 2. Study Sample Demographics of Fifth-Grade Students (Potential of 142 Intervention and 170 Comparison Students) in 4 Schools in Pawtucket, RI, School District

\begin{tabular}{|c|c|c|c|c|c|c|c|c|}
\hline \multirow[b]{2}{*}{ Continuous Variables } & \multicolumn{2}{|c|}{ Intervention } & \multicolumn{2}{|c|}{ Comparison } & \multicolumn{2}{|c|}{ Total } & \multirow[b]{2}{*}{$\boldsymbol{t}^{\mathrm{a}}$} & \multirow[b]{2}{*}{$\boldsymbol{P}$} \\
\hline & Mean \pm SD & $\mathbf{n}$ & Mean \pm SD & $\mathbf{n}$ & Mean \pm SD & $\mathbf{n}$ & & \\
\hline Age, y & $10.16 \pm 0.44$ & 140 & $10.22 \pm 0.45$ & 166 & $10.19 \pm 0.45$ & 306 & -1.02 & .31 \\
\hline Baseline fruit $^{\mathrm{b}}$ & $2.38 \pm 1.45$ & 138 & $2.40 \pm 1.53$ & 168 & $2.40 \pm 1.49$ & 306 & -.121 & .90 \\
\hline Baseline vegetables $^{\mathrm{b}}$ & $1.86 \pm 1.38$ & 138 & $2.01 \pm 1.43$ & 160 & $1.94 \pm 1.40$ & 298 & -.926 & .36 \\
\hline $\begin{array}{l}\text { Baseline policy, systems, } \\
\text { and environmental } \\
\text { knowledge }^{c}\end{array}$ & $3.85 \pm 1.66$ & 142 & $3.24 \pm 1.67$ & 167 & $3.52 \pm 1.69$ & 309 & 3.217 & .001 \\
\hline $\begin{array}{l}\text { Baseline fruit and } \\
\text { vegetable knowledge }\end{array}$ & $4.21 \pm 1.60$ & 142 & $3.70 \pm 1.70$ & 167 & $3.94 \pm 1.67$ & 309 & 2.713 & .007 \\
\hline Categorical Variables & n (\%) & & n (\%) & & n (\%) & & $\chi^{2 d}$ & $\boldsymbol{P}$ \\
\hline \multicolumn{9}{|l|}{ Gender } \\
\hline Male & $71(51)$ & & $88(52)$ & & $159(51)$ & & .001 & .10 \\
\hline Female & $68(49)$ & & $82(48)$ & & $150(49)$ & & & \\
\hline Total & $139(45)$ & & $170(55)$ & & $309(100)$ & & & \\
\hline \multicolumn{9}{|l|}{ Language spoken $^{e}$} \\
\hline Spanish & $44(31)$ & & $68(41)$ & & $112(36)$ & & 2.59 & .11 \\
\hline Other & $97(69)$ & & $99(59)$ & & $196(64)$ & & & \\
\hline Total & $141(46)$ & & $167(54)$ & & $308(100)$ & & & \\
\hline
\end{tabular}

andependent-samples $t$ test; ${ }^{\text {b }}$ Baseline values are for the number of times fruit was eaten the previous day the or number of times vegetables were eaten the previous day, on a scale of $0-5$; ' Policy, systems, and environment knowledge on a scale of $0-7$ (in which $0=$ low and $7=$ high), and fruit and vegetable knowledge on a scale of $0-9$ (in which $0=$ low and $9=$ high);

dPearson chi-square (continuity correction); ${ }^{\mathrm{e}}$ Based on the question, Do you speak Spanish at home? 
Process evaluation qualitative results. Four themes emerged from the qualitative assessments. The first was that students, school staff, and EFNEP educators enthusiastically endorsed the PSE activities, as evidenced from the following participant feedback:

If this is the first school in Pawtucket, RI, to do this program, you guys did a really, really good job. (Student)

I would do it again because I liked having a choice in cafeteria. (Student)

Students were willing to participate and showed a lot of enthusiasm. They had many ideas. (Educator)

The students really enjoyed taste testing the recipes. It was nice to see a different program that the students really enjoyed getting involved in. (Health Teacher)

Both cafeterias were very excited and looked like the kids really enjoyed Recipe Day. (Foodservice manager)

Students were excited about the whole event, especially having the recipe on the lunch menu. (Educator)

I think this was a great program and I would like to see it again. (Teacher)

The recipe contest was awesome and the kids really enjoyed the lessons. (Principal)

The cafeteria was in a buzz and really excited. (Wellness Committee member)

The second and most commonly mentioned theme that school staff voiced as a result of this intervention was student empowerment. Most agreed that the lessons and activities increased the students' self-confidence in requesting the $\mathrm{FV}$ they wanted to see offered more in school and at home:

The program made them realize they had a voice in their school and were being heard. They realized they had power to make changes in their school. (Teacher)

It definitely empowered the students and it's always good to get a different perspective from different speakers. (Teacher)

I have had parents come up to me saying their kids are asking them to try new fruits and vegetables. (Principal)

In addition, a third theme identified by this project was that all students from both schools attributed making positive dietary changes to being the result of this intervention:

I asked Mom to buy more carrots when I had a recipe. I like them now. (Student)

Before, I didn't eat lots of fruits and vegetables; now I eat tomatoes, lettuce, apples, banana, grapes. (Student)

I asked Mom to put fruits and vegetables in [the] refrigerator where I can see them. (Student)

I didn't want to try new foods; now I ask Mom to buy new fruits and vegetables so I can try them. (Student)

Whereas fidelity, dose, and reach were high throughout the PSE intervention (Table 3 ), qualitative results revealed a fourth theme of barriers to the project. A major barrier throughout the intervention was miscommunication between EFNEP educators and classroom health teachers, and between these teachers and other school staff involved in the activities, such as the art teacher. In addition, there were scheduling problems in teaching the FFVP Nutrition Education Curriculum during the intervention; health teachers reported that in the intervention group only 1 FFVP Nutrition Education Curriculum lesson was taught at 1 school and 5 of 8 lessons were taught at the other school. In the comparison group, 3 lessons were taught at 1 school and 6 were taught at the other school:

Teachers seemed confused about what is happening after being originally excited about it. (Educator)

There was miscommunication with the art teacher and there was confusion as to who was teaching what. (Teacher)

Respondents indicated that lessons were too long (lasting 24-40 minutes instead of the intended 20 minutes) and too wordy and that the 2-week delivery approach was a major struggle:

I may have to summarize lessons more to ensure more time is available to complete group work. (Educator)

I realized I needed to explain words when mentioning the list of barriers categories. (Educator)

The program was delivered every 2 weeks and a lot of students forgot what they had learned on the previous lesson. Timing was the hardest. (Teacher)

Outcome evaluation quantitative results. The intervention group scored significantly higher than the comparison group on baseline PSE knowledge assessment $(t=3.22 ; P=.001)$ and FV knowledge $(t=2.71 ; P=.007)$. Whereas there were no significant changes in FV consumption between or within groups from pre- to postintervention, the intervention group scored significantly higher after adjusted for before as a covariate for PSE knowledge and FV knowledge (Table 4). Intervention PSE knowledge scores were significantly higher than were scores from comparison schools after the intervention $\left(\mathrm{F}_{37.56}\right.$; $P<.001)$ as were FV knowledge scores $\left(\mathrm{F}_{3.94} ; P=.04\right)$; PSE knowledge increased within both groups and FV 
Table 3. Details and Outcomes of the Process Evaluation of EMPOWER

Evaluation Element

Fidelity and

dose delivered

Dose received
Instrument

Fidelity checklist

Observation checklist

Fidelity checklists

Handwritten notes

Returned take-home
assignments

Graded rubrics

Estimated reach

\section{Details Collected}

Lesson objectives met for lessons 1-10

Lesson objectives met for lessons 2, 6, and 8

Attentiveness: $1=$ not at all to $5=$ very Understanding: $1=$ nothing to $5=$ everything

Observations

Completion of
assignment
Whether students
understood lesson
and/or activity
objectives

Number of students/ lesson
Evaluator

EFNEP

educators

SNAP-Ed staff $100 \%$ of lessons delivered

EFNEP

educators

Student attentiveness $=92 \%$

Student

understanding $=90 \%$

\section{EFNEP}

educators

Students actively participated and were engaged in all lessons, particularly in games and group activities.

Lessons 4 and 9 activities were most confusing for students.

Objectives in lessons 1, 4, and 9 were not always met owing to lesson length.

Some educators struggled to keep student discourse and classroom order.

Overall, educators agreed students were excited about the intervention.

\section{EFNEP \\ $75 \%$ assignment completion}

educators

SNAP-Ed staff

Lesson 5: Writing Recipes $100 \%$ lesson taught $58 \%$ recipes were submitted $21 \%$ met all rubric guidelines $70 \%$ were fruit/vegetables based

Average score $=4.7 / 7$

Lesson 6: Making Requests 93\% lessons taught

$39 \%$ submitted

$71 \%$ met all rubric guidelines

Average score $=5.5 / 6$

Lesson 8: Persuasive Messages

94\% lessons taught

97\% submitted

$69 \%$ met all rubric guidelines

Average score $=1.5 / 2$

Each lesson exposed about 135 students to lesson content 
Table 3. (Continued)

Evaluation Element

Perception

of program

Key informant semistructured interview scripts

\section{EFNEP focus group script}

Wellness committee meeting minutes
Details Collected

Successes, barriers, challenges captured with 5 students from each intervention school (2)

Script pilot-tested with 5 fifth-grade students in nonparticipatory school

\section{Successes, barriers, challenges captured with 1 principal, 1 foodservice represen- tative, 2 health teach- ers, and 1 wellness committee member Questions reviewed and edited by SNAP- Ed staff member with previous interviewing experience \\ Researcher

Researcher

Successes, barriers, challenges captured by 3 study-involved EFNEP staff members Previously tested questions from other SNAP-Ed interventions
Evaluator

Researcher

Researcher

.

\section{Overall Findings}

Enjoyed creating posters

Particularly recall discussing barriers to eating fruits and vegetables

Liked recipe taste testing the most

All would repeat the project if given the chance

All attributed making dietary changes to intervention

Student struggled with lessons delivered every other week

Miscommunication between educators and school staff

Wordiness of lessons

Recipe taste testing most successful activity

Student empowerment most perceived effect of intervention

Lessons were lengthy and wordy and some were difficult for students

Miscommunication between researchers and school staff

University of Rhode Island Fresh Fruit and Vegetable Program not being taught in classrooms

Timing of lessons every other week

Researcher Overall, pleased with outcome of the intervention.
Committee meetings recorded to track policy changes

\footnotetext{
EFNEP indicates Expanded Food and Nutrition Education Program; EMPOWER, Empowering Urban School Children to Increase Fruit and Vegetable Consumption Through EFNEP-Enhanced PSE Interventions; SNAP-Ed, Supplemental Nutrition Assistance Program-Education.
}

knowledge increased within the comparison group $(P<.05)$.

\section{DISCUSSION}

The purpose of this study was to conduct a comprehensive process evaluation of a school-based PSE change intervention called EMPOWER, as well as a short-term outcome evaluation. The primary aim was to assess the intervention's fidelity, dose, and reach as well as its perception by various key informants and staff; the secondary aim was to assess pre-post outcomes compared with a no-PSE treatment school. The process evaluation followed the comprehensive guide described by Saunders et $\mathrm{al}^{21}$ and its results were used to fine-tune the intervention.

Overall, both students and school staff reported liking the intervention and reported that students felt more empowered. Similar to other schoolbased interventions, ${ }^{30,31}$ hands-on, engaging activities (which in this study included recipe taste testing, creation of promotional posters, polling on Recipe Day, and lesson games) proved to be the most popular aspects of the intervention. The end result of these activities was that the recipes developed were added to the foodservice cycle menu. The qualitative results indicated that students reported increased self-confidence and empowerment in having a voice in both their school community and 
Table 4. Change in Students' Behavior and Knowledge From Pre- to Postintervention, by Group

\begin{tabular}{|c|c|c|c|c|c|c|}
\hline Variables & Pre (Mean \pm SD) & Post (Mean \pm SD) & $\begin{array}{l}\text { Within-Group } \\
\text { Change }(t / P)^{\mathrm{a}}\end{array}$ & $\begin{array}{c}\text { Adjusted Post }^{\mathrm{b}} \\
(\text { Mean } \pm \text { SE) }(95 \% \text { Cl) }\end{array}$ & $\begin{array}{l}\text { Between-Group } \\
\text { Difference }^{C}(F)\end{array}$ & $P^{c}$ \\
\hline $\begin{array}{l}\text { Intervention } \\
(\mathrm{n}=129)^{\mathrm{d}}\end{array}$ & $4.21 \pm 2.38$ & $4.16 \pm 2.36$ & $.282 / P=.78$ & NA & \multirow{3}{*}{0.001} & \\
\hline & & & & & & \\
\hline $\begin{array}{l}\text { Comparison } \\
\qquad(n=139)^{d}\end{array}$ & $4.37 \pm 2.53$ & $4.32 \pm 2.78$ & $.226 / P=.23$ & NA & & \\
\hline $\begin{array}{l}\text { Comparison } \\
(n=145)\end{array}$ & $3.30 \pm 1.65$ & $3.68 \pm 1.65$ & $2.30 / P=.02$ & $3.76 \pm 0.130(3.50-4.02)$ & 37.56 & .001 \\
\hline \multicolumn{6}{|c|}{ Fruit and vegetable knowledge ${ }^{e}$} & \\
\hline $\begin{array}{l}\text { Intervention } \\
(\mathrm{n}=133)\end{array}$ & $4.20 \pm 1.56$ & $4.58 \pm 1.93$ & $1.96 / P=.05$ & $4.52 \pm 0.151(4.22-4.82)$ & 3.94 & .05 \\
\hline
\end{tabular}

$\mathrm{Cl}$ indicates confidence interval; NA, not available.

${ }^{\mathrm{a}}$ Paired $t$ test; ${ }^{\mathrm{b}}$ Post value adjusted for pre as a covariate for knowledge items owing to baseline differences between groups; ${ }^{\mathrm{C}}$ Between-group difference for fruit and vegetable intake repeated-measures ANOVA; between-group differences for knowledge ANOVA, post adjusted for pre as covariate; ${ }^{\mathrm{d} V a l u e s}$ are for the number of times fruit was eaten the previous day or the number of times vegetables were eaten the previous day, on a scale of $0-5$; ${ }^{\mathrm{e}}$ No baseline difference between groups (no adjustment necessary). 
family environment as a result of these activities. Increasing student engagement is an integral piece in ensuring an intervention's success. ${ }^{32-34}$

Fidelity, dose, and reach were high. The high degree of fidelity of the PSE intervention seen in this study compares favorably with those that also used self-reported curriculum fidelity measurements and observations, ${ }^{35,36}$ as does that of dose. ${ }^{30,32,36}$ However, the dose of the health teacher who taught the FFVP Nutrition Education Curriculum was low; this was similar to finding by Helitzer et al, ${ }^{37}$ who reported that some school teachers were not following lessons entirely. In studies that had low implementation rates, lessons were delivered by school staff rather than research staff, which may explain their outcomes. Studies such as It's Your Move ${ }^{34}$ and High $5,^{31}$ in which intervention curricula were delivered by research staff, reported implementation rates similar to the PSE curriculum in the current study.

As hypothesized, postintervention PSE knowledge scores were significantly higher than those from comparison schools, which indicated that the intervention was effective in increasing PSE knowledge. This increase in PSE knowledge was consistent with qualitative results indicating greater empowerment. To the authors' knowledge, no other study looked at an increase in PSE knowledge or empowerment in fifth-graders. Although both the intervention and comparison schools increased their FV knowledge scores, the intervention group had a significantly higher increase in scores compared with the comparison group. This finding is similar to that in other studies. ${ }^{35}$ However, the current study found no change in the intake of FV. This is in contrast to other elementary school-based PSE interventions that found significant increases in FV as well as increases in nutrition knowledge. ${ }^{15,18,19}$ It is possible that the lack of change in FV intake found in the current study was related to the insensitivity of the survey instrument, because qualitative results found perceived FV behavior change by the students. It is equally possible that intervention activities were insufficient to change FV intake. Future research is needed to explore what behavioral effects, if any, were associated with the intervention.

Although there were several strengths to this study, there were limitations. Schools in this study were not randomly selected and baseline differences (although accounted for) were observed, which limits generalizability. Although the researchers observed 3 lessons, the majority of fidelity information was supplied by the EFNEP educators, which may have introduced respondent bias. Furthermore, teachers and students might have been inclined to give socially desirable answers. In addition, although responses were recorded as accurately as possible by a notetaker, interviews and focus group responses were not audio recorded. This decision was made to encourage student participation. According to Gibson, ${ }^{38}$ at-risk minority students have low confidence in verbal group participation, and "choosing the least intrusive [approach] might be preferred for young children." In addition, a single researcher coded and analyzed qualitative data. These limitations may have led to overestimation of intervention effects and perceptions. Schools were not measured on the same day of the week and different foods were available at different schools, which may have affected outcomes. Finally, dietary assessments with children are challenging and the accuracy of the FV assessment instrument is questionable. ${ }^{39}$ The FV Checklist used in this study may not have been sensitive enough to assess change.

\section{IMPLICATIONS FOR RESEARCH AND PRACTICE}

Results from this pilot study can be used to design future school-based PSE change interventions. Focusing on student empowerment may lead to longer-term changes in FV intake and knowledge. Future PSE FV interventions might explore delivering key concepts in simpler language, more interactively with lessons of shorter duration with increased frequency. There also needs to be better communication between intervention and school staff. Future interventions could consider incorporating preimplementation meetings with classroom teachers, regular check-ins to avoid confusion of teaching roles, and integration of the FFVP Nutrition Education Curriculum into the PSE curriculum, which would reduce the need for coordination between intervention and school staff. All of these changes have been incorporated into an expansion of the program entitled SNAP-Ed Students Take Charge, which is currently provided in 2 inner-city school sytems in Central Falls and Providence, RI. Future research needs more sensitive assessment tools and incorporation of full-scale observations of curriculum delivery to determine fidelity as well as assess long-term outcomes of PSE interventions in schoolchildren.

\section{ACKNOWLEDGMENTS}

This study was funded by the US Department of Agriculture Regional Nutrition Education and Obesity Prevention Centers of Excellence, EFNEP, and the University of Rhode Island/State of Rhode Island Department of Human Services SNAP-Ed.

\section{REFERENCES}

1. Brennan L, Castro S, Brownson RC, Claus J, Orleans CT. Accelerating evidence reviews and broadening evidence standards to identify effective, promising, and emerging policy and environmental strategies for prevention of childhood obesity. Ann Review Public Health. 2011;32:199-223.

2. Kegler MC, Honeycutt S, Davis M, et al. Policy, systems, and environmental change in the Mississippi Delta: considerations for evaluation design. Health Educ Behav. 2015;42(1 suppl):57S-66S

3. Frieden TR. A framework for public health action: the health impact pyramid. Am J Public Health. 2010;100:590-595.

4. Bunnell R, O'Neil D, Soler R, et al. Fifty communities putting prevention to work: accelerating chronic disease 
prevention through policy, systems and environmental change. J Comm Health. 2012;37:1081-1090.

5. Lieberman L, Golden SD, Earp JAL. Structural approaches to health promotion: what do we need to know about policy and environmental change. Health Educ Behav. 2013;40:520-525.

6. Kumanyika SK, Parker L, Sim LJ, eds. Bridging the Evidence Gap in Obesity Prevention: A Framework to Inform Decision Making. Washington, DC: National Academies Press; 2010.

7. Hard A, Uno C, Koch PA. The importance of nutrition education in the Child Nutrition Reauthorization 2015. http://www.tc.columbia.edu/media/ media-library-2014/centers/tisch-center/Nutrition-Ed-White-Paper-09.14. pdf. Accessed September 6, 2018.

8. Perera T, Frei S. Improving nutrition education in U.S. elementary schools: challenges and opportunities. J Educ Pract. 2015;6:41-50.

9. Racey M, O'Brien C, Douglas S, Marquez O, Hendrie G, Newton G. Systematic review of school-based interventions to modify dietary behavior: does intervention intensity impact effectiveness. $J$ Sch Health. 2016;86:452-463.

10. Evans CE, Christian MS, Cleghorn CL, Greenwood DC, Cade JE. Systematic review and meta-analysis of schoolbased interventions to improve daily fruit and vegetable intake in children aged 5 to 12 y. Am J Clin Nutr. 2012;96:889-901.

11. Hoelscher DM, Kirk S, Ritchie L, Cunningham-Sabo L. Position of the Academy of Nutrition and Dietetics: interventions for the prevention and treatment of pediatric overweight and obesity. $J \mathrm{Am}$ Diet Assoc. 2013;113:1375-1394.

12. Story M, Nanney MS, Schwartz MB. Schools and obesity prevention: creating school environments and policies to promote healthy eating and physical activity. Milbank Q. 2009;87:71-100.

13. Mager U, Nowak P. Effects of student participation in decision making at school: a systematic review and synthesis of empirical research. Educ Res Rev. 2012;7:38-61.

14. Dietary Guidelines for Americans Committee. A closer look at current intakes and recommended shifts: 2015-2020 Dietary Guidelines. http://health.gov/ dietaryguidelines/2015/guidelines/chapter-2/a-closer-look-at-current-intakesand-recommended-shifts/\#subnav-4. Accessed September 6, 2018.

15. Scherr RE, Linnell JD, Dharmar M, et al. A multicomponent, school-based intervention, the Shaping Healthy Choices Program, improves nutritionrelated outcomes. J Nutr Educ Behav. 2017;49:368-379.

16. Olsho LEW, Klerman JA, Ritchie L, Wakimoto P, Webb KL, Bartlett S. Increasing child fruit and vegetable intake: findings from the US Department of Agriculture Fresh Fruit and Vegetable Program. J Acad Nutr Diet. 2015;115:1283-1290.

17. Tuuri G, Zanovec M, Silverman L, et al. "Smart Bodies" school wellness program increased children's knowledge of healthy nutrition practices and self-efficacy to consume fruit and vegetables. Appetite. 2009;52:445-451.

18. Coleman KJ, Shordon M, Caparosa SL, Pomichowski ME, Dzewaltowski DA. The healthy options for nutrition environments in schools (Healthy ONES) group randomized trial: using implementation models to change nutrition policy and environments in low income schools. Int $J$ Behav Nutr Phys Act. 2012;9:80-96.

19. Campbell AC, Barnum D, Ryden V, Ishkanian S, Stock S, Chanoine J-P. The effectiveness of the implementation of Healthy Buddies, a school-based, peer-led health promotion program in elementary schools. Can J Diabetes. 2012;36:181-186.

20. US Department of Agriculture. Fruit and Vegetable Program. https://www. fns.usda.gov/ffvp/fresh-fruit-and-vegetable-program. Accessed September 6, 2018.

21. Saunders RP, Evans MH, Joshi P. Developing a process-evaluation plan for assessing health promotion program implementation: a how-to guide. Health Prom Pract. 2005;6:134-147.

22. US Census Bureau. Rhode Island QuickFacts from the US Census Bureau. http://www.census.gov/quickfacts/table/ PST045215/4454640. Accessed September 6, 2018.

23. Rhode Island KIDS COUNT. Rhode Island KIDS COUNT Factbook. http://www.rikidscount.org/Portals/0/ Uploads/Documents/Factbook\% 202016/2016\%20Rhode\%20Island\% 20KIDS\%20COUNT\%20Factbook.pdf. Accessed September 6, 2018.
24. Rhode Island Department of Education. CNP program data and finances. http://www.ride.ri.gov/cnp/ProgramDataFinances/CNPProgramDataFinances.aspx. Accessed September 6, 2018.

25. Wojcicki JM, Heyman MB. Healthier choices and increased participation in a middle school lunch program: effects of nutrition policy changes in San Francisco. Am $J$ Public Health. 2006;96:1542-1547.

26. US Department of Agriculture, Food and Nutrition Service. SNAP-Ed guidance. https://snaped.fns.usda.gov/snap/ Guidance/FY2018SNAP-EdPlanGuidance.pdf. Accessed September 6, 2018.

27. Townsend MS, Sylvia KG, Martin A, Metz D, Wooten-Swanson P. Improving readability of an evaluation tool for low-income clients using visual information processing theories. $J$ Nutr Educ Behav. 2008;40:181-186.

28. Collins D. Pretesting survey instruments: an overview of cognitive methods. Qual Life Res. 2003;12(3):229-238.

29. Elo S, Kyngäs H. The qualitative content analysis process. $J$ Adv Nurs. 2008;62:107-115.

30. Christian MS, Evans CEL, Ransley JK, Greenwood DC, Thomas JD, Cade JE. Process evaluation of a cluster randomised controlled trial of a school-based fruit and vegetable intervention: Project Tomato. Public Health Nutr. 2012;15:459-465.

31. Reynolds KD, Franklin FA, Leviton LC, et al. Methods, results, and lessons learned from process evaluation of the High 5 school-based nutrition intervention. Health Educ Behav. 2000;27:177-186.

32. Campbell R, Rawlins E, Wells S, et al. Intervention fidelity in a school-based diet and physical activity intervention in the UK: Active for Life Year 5. Int J Behav Nutr Phys Act. 2015;12:141155.

33. Jago R, Rawlins E, Kipping RR, et al. Lessons learned from the AFLY5 RCT process evaluation: implications for the design of physical activity and nutrition interventions in schools. BMC Public Health. 2015;15:946-947.

34. Mathews LB, Moodie MM, Simmons AM, Swinburn BA. The process evaluation of It's Your Move!, an Australian adolescent community-based obesity prevention project. BMC Public Health. 2010;10:448-448.

35. Davis M, Baranowski T, Resnicow K, et al. Gimme 5 fruit and vegetables for 
fun and health: process evaluation Health Educ Behav. 2000;27:167-176.

36. McGraw SA, Stone EJ, Osganian SK, et al. Design of process evaluation within the Child and Adolescent Trial for Cardiovascular Health (CATCH). Health Educ Q. 1994(suppl 2):S5-S26.
37. Helitzer DL, Davis SM, Gittelsohn J, et al. Process evaluation in a multisite, primary obesity-prevention trial in American Indian schoolchildren. Am J Clin Nutr. 1999;69(4 suppl):816S-824S.

38. Gibson F. Conducting focus groups with children and young people: strategies for success. $J$ Res Nurs. 2007;12:473-483.

39. Livingstone MB, Robson PJ, Wallace JM. Issues in dietary intake assessment of children and adolescents. Br J Nutr. 2004;92(suppl 2):S213-S222.

\section{Shirley's Picks-New Resources}

\section{Podcasts}

Shirley's Picks are short, 1-minute podcasts that summarize each issue's New Resources. Shirley Camp, MS, RD, LDN, JNEB's New Resources Editor, quickly provides readers with convenient access to the books, textbooks, booklets, storybooks, curricula, Web sites, audiovisuals, and other nutrition education featured in JNEB. More information is available at http:/ / www.jneb.org/content/ resources. 